\title{
Mobilidade sobre rodas: a percepção de pais de crianças com paralisia cerebral
}

\author{
Mariana Volpinia ${ }^{a}$, Marina de Brito Brandáo ${ }^{b}$, Lívia Álvares Rabelo Pereirac, \\ Marisa Cotta Mancini ${ }^{\mathrm{d}}$, Marcella Guimaráes Assis ${ }^{\mathrm{e}}$
}

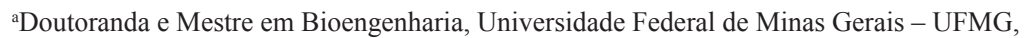
Professora da Faculdade Estácio de Sá de Belo Horizonte, Supervisora técnica da Oficina de Órteses, Associação Mineira de Reabilitação - AMR, Belo Horizonte, MG, Brasil

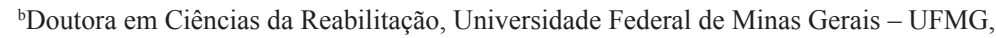
Coordenadora do Núcleo de Ensino e Pesquisa da Associação Mineira de Reabilitação, Professora da Faculdade de Ciências Médicas de Minas Gerais e da Fundação Mineira de Educação e Cultura - Universidade FUMEC, Belo Horizonte, MG, Brasil

'Pós-graduada em Terapia Comportamental, Pontifícia Universidade Católica de Minas Gerais - PUCMINAS, Terapeuta ocupacional, Fundação Mineira de Educação e Cultura - Universidade FUMEC, Belo Horizonte, MG, Brasil

${ }^{\mathrm{d}}$ Doutora em Rehabilitation Science, Boston University - BU, Boston, MA, Estados Unidos, Professora titular, Departamento de Terapia Ocupacional e Programa de Pós-graduação em Ciências da Reabilitação, Pró-Reitora Adjunta de Pesquisa, Universidade Federal de Minas Gerais - UFMG, Belo Horizonte, MG, Brasil

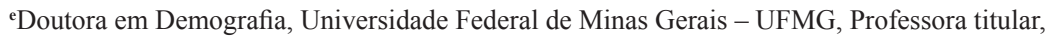
Departamento de Terapia Ocupacional e Programa de Pós-graduação em Ciências da Reabilitação, Universidade Federal de Minas Gerais - UFMG, Belo Horizonte, MG, Brasil
\end{abstract}

\begin{abstract}
Resumo: Crianças com paralisia cerebral (PC) frequentemente utilizam dispositivos de mobilidade como facilitadores de sua funcionalidade e independência, o que impacta positivamente também na qualidade de vida do cuidador. Considerando a abordagem da prática centrada na família, os pais assumem papel decisivo em diferentes etapas do processo terapêutico, norteando diversas ações de profissionais da área da reabilitação na busca, desenvolvimento e/ou adaptação de equipamentos que atendam às necessidades específicas da clientela interessada. Neste estudo objetivou-se compreender a percepção dos pais de crianças com PC sobre a utilização da cadeira de rodas no cotidiano de seus filhos. O presente estudo qualitativo utilizou entrevistas semiestruturadas com 16 pais de crianças cadeirantes com paralisia cerebral, atendidas na Associação Mineira de Reabilitação. Análise de conteúdo pautou a categorização de temas que emergiram das entrevistas. Os resultados expressos nas categorias temáticas "O olhar sobre o uso cotidiano" e "O olhar sobre o equipamento" apontaram características relacionadas aos benefícios do uso da cadeira de rodas na promoção da participação da criança nos ambientes de casa, escola e comunidade, bem como diferentes aspectos da cadeira de rodas que favoreceram e dificultaram a sua utilização no dia a dia dessas crianças.
\end{abstract}

Palavras-chave: Cadeiras de Rodas, Cotidiano, Paralisia Cerebral, Tecnologia Assistiva.

\section{Wheeled mobility: the perception of parents of children with cerebral palsy}

\begin{abstract}
Children with cerebral palsy (CP) often use mobility devices as facilitators of their functionality and independence, and these devices may have a positive impact on their caregivers' quality of life. Considering a family-centered approach, parents assume a decisive role in different stages of the therapeutic process, guiding several actions of the rehabilitation professionals during the search, development and/or adaptation of equipment that meet the specific needs of customers. The aim of this research was to understand the perceptions of parents of children with CP on the use of the wheelchair in the daily routines of their children. This qualitative study used
\end{abstract}

Autor para correspondência: Marcella Guimarães Assis, Programa de Pós-graduação em Ciências da Reabilitação, Universidade Federal de Minas Gerais, Av. Antônio Carlos, 6627, Pampulha, CEP 31270-901, Belo Horizonte, MG, Brasil, e-mail: mga@ufmg.br Recebido em 19/11/2012; Aceito em 18/1/2013. 
semi-structured interviews with 16 parents of CP children who were wheelchair users assisted at 'Associação Mineira de Reabilitação'. Content analysis grounded the categorization of themes that emerged from the interviews. The results expressed in themes such as "The look on the daily routine" and "The look on the equipment" pointed out characteristics related to the benefits of the use of the wheelchair in promoting child participation at home, at school, and in community environments, as well as different features of wheelchairs that facilitate or hamper their use in children's daily routine.

Keywords: Wheelchairs, Daily Routine, Cerebral Palsy, Assistive Technology.

\section{Introdução}

Crianças com paralisia cerebral (PC) de moderada a grave frequentemente utilizam tecnologia assistiva como facilitadora de sua funcionalidade. A tecnologia assistiva consiste em serviços e equipamentos que visam promover independência no desempenho de atividades rotineiras (CAMPBELL et al., 2006; JUDGE, 2002). Atualmente, tem crescido o uso dos dispositivos de mobilidade, como a cadeira de rodas (JUDGE, 2002), principalmente por crianças e adolescentes com PC (OSTENSJO; CARLBERG; VOLLESTAD, 2005; SALMINEN et al., 2009). A utilização da cadeira de rodas, além de promover funcionalidade e independência dessa clientela, possibilita ampliação da participação social, impactando positivamente também na qualidade de vida do cuidador (GLUMAC et al., 2009; HENDERSON; SKELTON; ROSENBAUM, 2008).

A abordagem centrada na família é preconizada por diversos autores que enfatizam a necessidade de uma ação colaborativa entre pais e profissionais da reabilitação na tomada de decisóes clínicas em geral e, em específico, na prescrição de recursos de tecnologia assistiva (DUGAN; CAMPBELL; WILCOX, 2006; PARETTE; BROTHERSON, 2004). Parette e Brotherson (2004) argumentaram que o processo de prescrição de equipamentos deve-se pautar nas características da criança, do equipamento, nas necessidades e demandas da família e do serviço de reabilitação. Assim, os profissionais de reabilitação devem considerar não somente aspectos técnicos como correçáo de postura e posicionamento da criança, mas também as experiências e necessidades das crianças e de seus cuidadores e as características dos ambientes frequentados pela criança (JUDGE, 2002; DUGAN; CAMPBELL; WILCOX, 2006).

Considerando o modelo colaborativo que se estabelece entre pais e profissionais da reabilitaçáo na abordagem da prática centrada na família, os pais assumem papel decisivo em diferentes etapas do processo terapêutico, inclusive na escolha de equipamentos e na sua utilização nas rotinas familiares (DUGAN; CAMPBELL; WILCOX,
2006). Segundo Maloni et al. (2010), a percepção das mães sobre a deficiência dos filhos pode ser um determinante na busca pelos serviços de saúde e, consequentemente, no cuidado disponibilizado a essas crianças. Da mesma forma, a percepção dos pais sobre os utensílios de mobilidade a serem utilizados com os filhos influenciará na sua escolha e padrão de uso; compreender como os pais percebem e experimentam a utilizaçáo de equipamentos de mobilidade como opção de mobilidade funcional para os filhos é fundamental para os profissionais que atuam na reabilitação (WIART et al., 2004). Embora alguns autores (OSTENSJO; CARLBERG; VOLLESTAD, 2003, 2005; SALMINEN et al., 2009) tenham documentado a importância da cadeira de rodas na promoção da participação dessas crianças, é escasso o conhecimento sobre a percepção dos cuidadores de crianças com PC acerca da utilização desse equipamento na rotina diária (HENDERSON; SKELTON; ROSENBAUM, 2008; PALISANO et al., 2003). Tais informaçôes poderão nortear diversas açóes de profissionais $\mathrm{da}$ área da reabilitação na busca, desenvolvimento e/ou adaptação de equipamentos que atendam às necessidades específicas da clientela interessada, considerando as características dos contextos físico, atitudinal e social. O objetivo do presente estudo é compreender a percepção dos pais de crianças com PC sobre a utilização da cadeira de rodas no cotidiano dos filhos.

\section{Metodologia}

\subsection{Participantes}

O presente estudo utilizou abordagem qualitativa e foram selecionados, por conveniência, cuidadores principais, máes ou pais de crianças com PC de comprometimento motor grave, que utilizavam cadeiras de rodas do tipo monobloco com tilt ou com fechamento em X e eram atendidas na Associação 
Mineira de Reabilitação (AMR), em Belo Horizonte. Foram realizadas 16 entrevistas e o critério para interrupçáo foi o momento em que o surgimento de novos dados se tornou raro, caracterizando a saturação (TURATO, 2003).

Esse estudo foi aprovado pelo Comitê de Ética em Pesquisa em Seres Humanos da Universidade FUMEC (Fundação Mineira de Educação e Cultura) (ETIC 01/2011) e os pais que concordaram em participar voluntariamente do estudo assinaram o termo de consentimento livre e esclarecido. Nomes fictícios foram utilizados visando preservar o anonimato dos pais e das crianças.

\subsection{Coleta de dados}

Foram realizadas entrevistas semiestruturadas com os cuidadores das crianças. A entrevista consiste num processo de interação entre entrevistador e entrevistado para a obtenção de informaçóes sobre o fenômeno de interesse (HAGUETTE, 2000). Na entrevista semiestruturada, o entrevistador faz uso de roteiro com perguntas que direcionam a busca de informaçóes, sendo o entrevistado guiado acerca das áreas exploradas (SILVA et al., 2006). O roteiro de entrevista do presente estudo foi constituído por um primeiro grupo de perguntas descritivas sobre informaçôes sociodemográficas do cuidador e da criança, seguido por outro grupo que incluiu questôes relacionadas a representaçáo da cadeira de rodas, a utilização do equipamento no cotidiano familiar em diferentes cenários e a avaliação da cadeira pelo cuidador. Cada entrevista foi gravada e posteriormente transcrita.

\subsection{Análise dos dados}

Para análise das entrevistas, utilizou-se análise de conteúdo, que consiste de um conjunto de técnicas para obtenção de indicadores relevantes norteadores de inferência de conhecimentos relacionados ao tema estudado (BARDIN, 1997). A análise de conteúdo é composta por etapas que incluem pré-análise do material, por meio de leitura flutuante; exploração do material, com codificação dos dados em unidades; tratamento e interpretação dos dados, para a categorização de elementos (BARDIN, 1997).

\section{Resultados}

Os participantes do estudo foram 16 mães e pais de crianças e adolescentes com PC (Tabela 1). Os resultados foram agrupados em duas categorias: o olhar sobre o uso cotidiano e o olhar sobre o equipamento. A primeira categoria foi subdivida em três subcategorias: benefícios da cadeira de rodas para

Tabela 1. Informações descritivas sobre os cuidadores, as crianças e as cadeiras de roda.

\begin{tabular}{ccccccl}
\hline $\begin{array}{c}\text { Nome fictício } \\
\text { do cuidador }\end{array}$ & $\begin{array}{c}\text { Idade do } \\
\text { cuidador }\end{array}$ & $\begin{array}{c}\text { Nome fictício } \\
\text { da criança }\end{array}$ & $\begin{array}{c}\text { Idade da } \\
\text { criança }\end{array}$ & GMFCS* & Tipo de cadeira \\
\hline Dulce & 46 & Lucas & 10 anos & IV & Cadeira de rodas com tilt e mesa adaptada \\
Daise & 37 & Cristiano & 5 anos & V & Cadeira de rodas com tilt e mesa adaptada \\
Marisa & 38 & Yuri & 12 anos & V & Cadeira de rodas com tilt e mesa adaptada \\
Marta & 42 & João Paulo & 7 anos & IV & Cadeira de rodas com tilt e mesa adaptada \\
Horácio & 43 & Fábio & 3 anos & V & Cadeira de rodas com tilt e mesa adaptada \\
Gabriela & 40 & Jéssica & 12 anos & IV & Cadeira de rodas duplo X de alumínio \\
Joice & 47 & Thiago & 9 anos & IV & Cadeira de rodas com tilt e mesa adaptada \\
Silvia & 28 & Marcelo & 6 anos & IV & Cadeira de rodas com tilt \\
Carolina & 28 & Rafael & 10 anos & V & Cadeira de rodas com tilt e mesa adaptada \\
Priscila & 30 & Luiza & 12 anos & IV & Cadeira de rodas dobrável em X \\
Vanessa & 27 & Bernardo & 10 anos & IV & Cadeira de rodas dobrável em X \\
Bruna & 32 & Flávio & 13 anos & IV & Cadeira de rodas dobrável em X em alumínio \\
Joana & 29 & Ramon & 11 anos & IV & Cadeira de rodas com tilt e mesa adaptada \\
Renata & 32 & Tássia & 7 anos & III & Cadeira de rodas com tilt e mesa adaptada \\
Poliana & 31 & Matheus & 8 anos & IV & Cadeira de rodas com tilt e mesa adaptada \\
Shirley & 32 & Leandro & 3 anos & IV & Cadeira de rodas com tilt e mesa adaptada \\
\hline
\end{tabular}

*GMFCS: Sistema de Classificação da Função Motora Grossa, que classifica a função de mobilidade de crianças com paralisa cerebral em cinco níveis, sendo que o nível III é atribuído a crianças que andam com auxílio ou suporte, o nível IV, a crianças que utilizam tecnologia assistida para mover-se, e o nível $\mathrm{V}$, a crianças cuja mobilidade é gravemente comprometida, mesmo com o uso de tecnologia assistiva (PALISANO et al., 1997). 
criança e seu cuidador, contextos de utilização da cadeira de rodas e acessibilidade física e atitudinal.

\subsection{O olhar sobre o uso cotidiano}

\subsubsection{Benefícios da cadeira de rodas para a criança e o seu cuidador}

Os cuidadores relataram que o uso da cadeira de rodas trouxe benefícios não só para a rotina da criança como também para a deles. Com relaçáo à criança, os relatos relacionaram-se ao uso habitual: "[...] pra sair na rua e pegar ônibus, tudo. Tudo é com a cadeira." (Bruna), posicionamento "[...] é o posicionamento do Rafael, onde ele está vendo todas as coisas e onde que ele fica bem." (Carolina), conforto e segurança

[A cadeira] tem o posicionamento, que é o jeito que ele fica confortável, o conforto dele... E de não cair, porque a cadeira segura até nessa questão, de que ele não vai para um lado, não vai pro outro. Não tem perigo dele cair. (Carolina).

Quanto aos benefícios para a rotina do cuidador, foi destacada a diminuição da carga física no transporte da criança:

Olha, me aliviou muito porque eu já tô com dores nos ossos, muita dor. Essa cadeira, pra mim, quando ela chegou, foi uma benção porque eu já tava cansada, e ele só crescendo. Eu já não tava aguentando mais, então pra mim foi uma maravilha, uma benção de Deus. A cadeira pra ele tá me ajudando muito. Muito mesmo. (Marta).

Outro aspecto ressaltado pelos cuidadores foi que o uso da cadeia de rodas para suas crianças proporcionou-lhes maior liberdade e tempo para realização de suas atividades:

[...] a cadeira de rodas representa assim a minha liberdade de poder trabalhar dentro da minha casa e fazer as minhas coisas. (Marisa), [...] enquanto eu estou nos meus afazeres, ele tá sentado na cadeira perto de mim, vou lá fora e levo comigo. (Shirley).

Esses relatos expressam uma ampliaçấo dos benefícios da cadeira de rodas náo só na vida da criança mas também na do cuidador, revelando a extensão da importância do equipamento na rotina familiar. "Tudo que a gente faz é naquela cadeira, né. Vamos pra rua, vamos ficar lá no bar, né. Ele vai comigo na mercearia, ele gosta." (Dulce).

Embora os pais tenham reconhecido benefícios do uso da cadeira de rodas na mobilidade, posicionamento, conforto e segurança da criança, eles reportaram certa insatisfação quanto ao uso do equipamento na constatação das limitações motoras do(a) filho(a):

A unica coisa que poderia, assim, que eu acho que ela apresenta de ruim é que a Luiza não anda, ela tá na cadeira, ela não anda [...] Eu queria que ela não precisasse usar, né, mas tem que usar. (Priscila); [...] eu queria que ela não tivesse que usar a cadeira, né, todas as mães têm esse desejo. (Renata).

\subsubsection{Contextos de utilização da cadeira de rodas}

Os contextos de utilização do equipamento, segundo relato dos pais, foram: a escola, a casa e a comunidade. Os pais informaram que a cadeira de rodas possibilitou a mobilidade necessária para o acesso à escola:

Pra escola é importante a cadeira porque sem a cadeira não tem como nem tá mandando ele pra escola. (Vanessa); Na escola ele tem atividade fora e dentro da sala que usa a cadeira. (Marisa).

Ainda em relação à escola, os pais ressaltaram a função da cadeira no melhor posicionamento da criança, promovendo a realização das atividades: "[...] na escola é bom por causa da mesa, né, e dele tá riscando, usando a mesa pra apoiar o caderno." (Dulce).

O relato de uso da cadeira de rodas em casa foi diversificado. Alguns pais reportaram uso contínuo na rotina da criança, estabelecendo-se um forte vínculo dela com o equipamento:

Já acorda e quer ia pra cadeira. Aí eu dou banho nele e ele vai pra cadeira. Às vezes eu deixo ele um pouquinho sentado no sofá, mas ele fica lá o tempo inteiro querendo a cadeira. Ele só não dorme naquela cadeira." (Dulce).

Outros pais relataram que o uso ocorreu somente durante atividades específicas: "Ele fica na cadeira quando tá vendo televisão ou quando eu tô fazendo estimulação visual" (Sílvia). Nas atividades de casa, os pais destacaram o uso do equipamento para alimentação, proporcionando posicionamento, segurança da criança e conforto para o cuidador:

Pra alimentação ela é fundamental, porque ele fica bem posicionado e eu fico com as mãos livres pra poder tá dando o alimento, limpando a boquinha, né. Enquanto que se ele estivesse no colo eu teria que tá com uma mão segurando, 
com a outra mão dando a comida, limpando a boca. Ficaria bem mais dificil." (Daise).

Uma mãe, entretanto, relatou dificuldade de uso do equipamento na alimentação:

Pra comer não, que eu tô usando essa cadeira há mais de um ano mas não consegui ainda me adaptar a como alimentá-lo na cadeira. Porque a posição correta de alimentar é a cadeira totalmente sentada, né, e ele não tem controle, então é um pouco difícil, ainda não consegui." (Shirley).

Outras atividades de casa nas quais a cadeira de rodas era utilizada foram: brincar em ambiente interno: "Eu ponho a mesinha com um brinquedo, um laptop, os brinquedos que ele gosta [...] vai brincar de colorir, massinha." (Poliana); e em ambiente externo: "E, assim, às vezes quando ela vai brincar com os colegas, vai brincar de bola, alguma coisa assim no terreiro, ai ela utiliza a cadeira de rodas." (Gabriela), no assistir televisão: "Ele fica na cadeira quanto tá vendo televisão." (Silvia) e em exercícios de reabilitação: "Eu gosto muito de fazer alongamento nos braços dele quando ele tá na cadeira, porque ele fica em uma posição bem bacana." (Daise).

Alguns pais relataram não usar o equipamento em casa: "Ah não, em casa ela não usa não." (Gabriela). As razóes para o não uso variaram de acordo com os atributos de capacidade da criança, tais como a possibilidade de manter-se sentada em cadeiras comuns: "Em casa ela fica sentada na cadeira da mesa, no sofá ou no banquinho." (Gabriela), com a percepção dos cuidadores acerca do incômodo da criança em permanecer longo período de tempo na cadeira de rodas: "Só que às vezes eu também tiro ela, não deixo o tempo todo, entendeu? $O$ dia inteiro. Eu tenho dó dela ficar o dia inteiro sentada na cadeira, então eu tiro ela." (Renata) e acerca da dificuldade de acessibilidade física:

A cadeira dele ficava muito no final do ônibus, eu já comentei? Porque onde eu moro é muito alto. Muito, muito alto, é impossivel subir e descer, mais ainda de cadeira. Então o que que acontecia, a gente não tinha carro, ai essa cadeira ficava no final do ônibus mesmo. Então ela ficava ali o mês inteiro, aí eu só usava pra sair. (Daise).

O uso do equipamento na comunidade, reportado pelos pais, possibilitou a participaçáo da criança em eventos familiares e no lazer em ambientes externos:

Passeio, festa de aniversário, clube, tudo o que eu vou eu levo a cadeira. (Carolina), Pra casa de parentes onde que eu vou que é longe, é tudo na cadeira. (Vanessa) bem como no acompanhamento das atividades do cuidador: "Comigo na mercearia ele vai, ele gosta.", "E para, se eu for em supermercado, padaria com ele, médico." (Dulce).

\subsubsection{Acessibilidade física e atitudinal}

Os pais destacaram algumas barreiras ambientais que dificultaram o uso da cadeira de rodas. Com relação à acessibilidade física, em ambientes comerciais e de serviços de saúde, seja pela disposição de mobiliários ou pela ausência de adaptaçóes, os pais tiveram dificuldades com o uso do equipamento:

Eu já tive vez que queria entrar num sacolão e não consegui passar entre as prateleiras, então eu não entrei. No supermercado também, que é muito estreito. (Bruna), Tem lugar que não é adaptado, não tem rampa. Que o elevador não é apropriado. Tipo, o hospital, o hospital não é adaptado. Não tem rampa. (Shirley).

Outras dificuldades relacionaram-se ao uso do transporte público e às condiçóes de ruas e calçamentos:

[...] acho que a maior dificuldade é essa, porque, pra entrar no ônibus, às vezes as pessoas têm que me ajudar. Porque não são todos os ônibus que têm elevador." (Bruna), "Tem rua mesmo que não tem como eu estar passando, por ter muito buraco, ter muito morro. Fica até dificil estar passando com a cadeira." (Vanessa).

Em relação à acessibilidade atitudinal, as dificuldades de aceitação social reportadas relacionaram-se à necessidade de auxílio para uso de serviços e ao preconceito:

\begin{abstract}
Já houve várias vezes, assim, de eu dar o sinal, o ônibus parar e eu ficar parada na porta, olhando quem é que vai me ajudar a subir com a cadeira. Parece que as pessoas, quando veem um deficiente em uma cadeira de rodas, eu não sei o que elas pensam. (Shirley), [...] na secretaria, às vezes tem gente que fala: 'Nossa, coloca uma criança na cadeira de rodas pra passar na frente. (Silvia), Ah, eu acho que o único aspecto negativo que eu vejo na cadeira não é com relação à cadeira em si não, é com relação ao preconceito das pessoas na rua. (Shirley).
\end{abstract}

\subsection{O olhar sobre o equipamento}

Os pais apontaram diferentes aspectos da cadeira de rodas que favoreceram ou dificultaram a sua utilização no dia a dia dos filhos. 
No relato dos pais sobre as inadequaçóes de partes específicas da estrutura da cadeira de rodas destacaram-se o tamanho do apoio de pé: "E também nessa parte do apoio dos pés, deveria ter assim... poderia ser mais flexivel, pra poder mexer mais, arrumar aquela parte dos pés." (Horácio), bem como o peso e o tamanho do equipamento. O peso foi mencionado como um problema pelos cuidadores cujas crianças utilizam a cadeira de rodas de ferro: "Ela é pesada. Muito pesada." (Daise). Uma mãe cujo equipamento de ferro foi substituído por um de alumínio ressaltou as vantagens da cadeira de rodas de material mais leve:

Olha, essa cadeira que ele tá agora - que é de aluminio, se eu não me engano o material - é perfeita, muito mais leve pra carregar. Mas a cadeira antiga - tem até muita criança que tem dela - a cadeira antiga é muito pesada. Muito pesada. Acho que não tem uma mãe que não fala do peso da cadeira. (Bruna).

Os relatos quanto ao tamanho do equipamento centraram-se na dificuldade de transporte da cadeira em carro ou ônibus: "Eu acho ela grande. A roda eu acho muito difícil de pôr no porta-malas." (Poliana). A dificuldade de acomodação do equipamento em porta-malas também foi atribuída ao sistema de fechamento. Essa queixa ocorreu com os pais de crianças que possuíam cadeiras de rodas monobloco com tilt, cujo sistema de assento separa-se do sistema de mobilidade, mas ambos não fecham, sendo considerado pouco práticas para transporte: “[...] essas cadeiras, elas são muito difíceis da gente colocar no bagageiro do carro, por ela náo fechar aquela parte que tem a roda." (Joana).

Outras partes da cadeira de rodas destacadas como inadequadas foram o sistema de freio:

E até mesmo pela altura do freio, eu acho o freio dela muito fraco, por ser uma cadeira grande, né, algumas delas são pesadas. Se tivesse como colocar mais freio nela seria bom. (Vanessa)

a haste lateral de tronco:

[...] só o que atrapalha às vezes é o ferrinho que tem do lado, que ele póe os braços, e aí aperta muito. A gente tem que voltar com o braço pra frente. (Carolina)

e o punho:

[...] onde você póe a máo pra levar... uma empunhadeira, vamos dizer, uma empunhadeira na cadeira. Poderia mudar e colocar em formato de bengala, pra por no carro. E também se houvesse a possibilidade de colocar uma regulagem, porque pra carregar a cadeira, en que sou alto, tenho que me encurvar todo, né. [...] Pra ficar um tamanho ideal pra uma pessoa mais alta, mais baixa, pra pessoa que vai conduzir, entendeu? (Horácio).

Algumas adaptaçóes realizadas em cadeiras de rodas não foram avaliadas como positivas, principalmente relacionadas ao encosto:

\section{[...] o que tá preocupando é esse encosto mesmo, que tá pra baixo do ombro e ele fica muito com o pescoşo pra trás. E ele ainda tem muita dificuldade pra se alimentar, então se ele tiver um apoio, ele melhora, sabe. (Bruna)}

ao tipo de estofado: "[...] eu acho que ela [cadeira] é muito quente, o estofado dela é quente." (Carolina), e ao uso de velcro: "[...] aqueles velcros de lado, aquele trem que prende muito o braço." (Joana). Entretanto, o uso de velcro também foi considerado importante para manutençáo do posicionamento da criança: “[...] aquele monte de velcro, aquela trenhada amarrada. Mas aquilo precisa, né. Pro Cristiano precisa de todos aqueles velcros, aqui no peito..." (Daise).

Cabe destacar que os pais também sugeriram a inclusão de adaptaçóes na cadeira de rodas, como a colocação de guarda-chuva: "Acho que faltou só um guarda-chuvas, porque igual hoje, que tá chovendo, é difícil pra gente segurar o guarda-chuvas e empurrar a cadeira. É difícil mesmo." (Marta).

\section{Discussão}

Os relatos dos pais ressaltaram percepçáo de efeitos positivos do uso da cadeira de rodas na rotina diária de seus filhos com PC. O uso da cadeira de rodas contribuiu para melhoria do desempenho das crianças e adolescentes em atividades como a alimentação e a realização de tarefas escolares, ampliou a participação deles no brincar, no lazer em ambientes externos e em eventos familiares.

Tais resultados são corroborados pelo estudo de Glumac et al. (2009), no qual pais de crianças com PC da República da Guatemala consideraram o uso do equipamento como elemento crucial para a promoção da participação da criança na vida familiar e comunitária. Uma característica essencial dos dispositivos de tecnologia assistiva é a facilitaçâo da interação da criança no ambiente, maximizando seu desempenho nas atividades da rotina diária (HENDERSON; SKELTON; ROSENBAUM, 2008; McDONALD; SURTEES; WIRZ, 2003). Assim, a cadeira de rodas, ao apresentar-se como método alternativo de mobilidade e proporcionar suporte postural adequado, contribui para o 
conforto, funcionalidade e participação da criança (GLUMAC et al., 2009).

Os pais, quando indagados acerca das barreiras ambientais que dificultavam a utilização da cadeira de rodas, identificaram barreiras físicas e atitudinais. Entre as barreiras físicas foram mencionadas a ausência de rampas e adaptaçóes e a inadequação dos meios de transporte públicos. Tais barreiras influenciam diretamente a estruturação da rotina familiar, uma vez que os pais precisam planejar as atividades e seus horários levando em consideração a necessidade de manipulação do equipamento (PAGLLUCA; ARAGÃO; ALMEIDA, 2007), o que pode representar maior sobrecarga para o cuidador (VASCONCELOS; PAGLLUCA, 2006).

Fatores sociais e atitudinais também foram citados como dificultadores do uso da cadeira de rodas. Para crianças com PC que apresentam grande dificuldade de mobilidade, o uso deste equipamento, por um lado, proporciona um método alternativo de mover-se no ambiente, facilitando inclusive o acesso a determinados locais, por outro, parece representar para os pais a marca permanente da incapacidade do(a) filho(a) (OSTENSJO; CARLBERG; VOLLESTAD, 2005). Tal realidade é de difícil aceitaçáo por parte dos pais, que costumam manter a esperança de que sua criança apresente melhora do quadro motor e possa adquirir a capacidade de deambular (GOFFMAN, 1988).

O processo de reconceitualização da deficiência, no qual os pais modificam a percepção sobre a incapacidade do filho, promove a aceitação e a valorização de métodos alternativos de mobilidade (SKAR, 2002; WIART et al., 2004). Nesse processo, os pais, que inicialmente atribuem a incapacidade do(a) filho(a) exclusivamente à limitação intrínseca da criança, posteriormente se deslocam para o entendimento desse processo como constituído por limitaçôes que a criança apresenta ao participar de atividades significativas, ressaltando assim a estrutura relacional (MALONI et al., 2010). Os pais frequentemente receiam que suas crianças sejam identificadas pela sociedade como incapazes e o uso de cadeira de rodas pode tornar-se fonte de estigma e preconceito social direcionados à criança e seus familiares, devido à visibilidade que o equipamento confere à diferença (CAHILL; EGGLESTON, 1995; GOFFMAN, 1988).

$\mathrm{O}$ uso da cadeira de rodas promoveu diminuição da demanda física do cuidador para o transporte da criança. A efetividade da tecnologia assistiva está associada, necessariamente, à promoção da independência funcional da criança, à diminuição da quantidade de assistência oferecida pelo cuidador e da atenção às demandas associadas aos cuidados diários da criança (OSTENSJO; CARLBERG; VOLLESTAD, 2005). Apesar da escassez de estudos sobre o impacto do uso de equipamentos assistivos na rotina dos cuidadores, as evidências disponíveis até o momento parecem convergir na constatação de que os pais podem se beneficiar do uso desses dispositivos (HENDERSON; SKELTON; ROSENBAUM, 2008), entre outros fatores, pela diminuição da demanda de cuidados à criança (GLUMAC et al., 2009; OSTENSJO; CARLBERG; VOLLESTAD, 2005).

No que tange às características estruturais do equipamento, os pais apontaram insatisfação com o tamanho e o peso da cadeira de rodas, o que é corroborado pelo estudo de McDonald, Surtees e Wirz (2003). Além disso, adaptações para melhoria do uso do equipamento, tais como modificaçóes no apoio dos pés, acoplamento de guarda-chuvas e adaptações para o cuidador movimentar a cadeira nem sempre são aprovadas pelos pais, ilustrando a necessidade de que as modificações sejam implementadas de forma individualizada e que contemplem as necessidades da criança, da família e do ambiente.

O presente estudo buscou apreender sobre a percepção dos pais de crianças com PC acerca do uso da cadeira de rodas na rotina diária de seus filhos. Os significados atribuídos pelos pais incluem a percepção de que ela é um equipamento facilitador da rotina diária mas também explicita socialmente a marcação da incapacidade permanente do(a) filho(a).

\section{Referências}

BARDIN, L. B. Análise de conteúdo. São Paulo: Martins Fontes, 1997.

CAHILL, S. E.; EGGLESTON, R. Reconsidering the stigma of physical disability: wheelchair use and public kindness. Sociological Quarterly, Carbondale, v. 36, n. 4, p. 681-698, 1995. http://dx.doi. org/10.1111/j.1533-8525.1995.tb00460.x

CAMPBELL, P. H. et al. A review of evidence on practices for teaching young children to use assistive technology devices. Topics in Early Childhood Special Education, Austin, v. 26, n. 1, p. 3-13, 2006. http://dx.doi.org/10. 1177/02711214060260010101

DUGAN, L. M.; CAMPBELL, P. H.; WILCOX, M. J. Making decisions about assistive technology with infants and toddlers. Topics in Early Childhood Special Education, Austin, v. 26, n. 1, p. 25-32, 2006. http://dx.doi.org/10. 1177/02711214060260010301

GLUMAC, L. K. et al. Guatemalan caregivers' perceptions of receiving and using wheelchairs donated for their children. Pediatric Physical Therapy, Baltimore, v. 21, n. 2, p. 167-175, 2009. PMid:19440126. http://dx.doi. org/10.1097/PEP.0b013e3181a34a2b 
GOFFMAN, E. Estigma: notas sobre a manipulação da identidade deteriorada. Rio de Janeiro: LTC Editora, 1988.

HAGUETTE, T. M. F. Metodologias qualitativas na sociologia. Petrópolis: Vozes, 2000.

HENDERSON, S.; SKELTON, H.; ROSENBAUM, P. Assistive devices for children with functional impairments: impact on child and caregiver function. Developmental Medicine and Child Neurology, London, v. 50, n. 2, p. 89-98, 2008. PMid:18177410. http://dx.doi. org/10.1111/j.1469-8749.2007.02021.x

JUDGE, S. Family-centered assitive technology assessment and intervention practices for ealy intervention. Infants and Young Children, Frederick, v. 15, n. 1, p. 60-68, 2002. http://dx.doi.org/10.1097/00001163-200207000-00009

MALONI, P. K. et al. Perceptions of disability among mothers of children with disability in Bangladesh: implications for rehabilitation service delivery. Disability and Rehabilitation, London, v. 32, n. 10, p. 845-854, 2010. PMid:20131951. http://dx.doi. org/10.3109/09638280903326063

McDONALD, R.; SURTEES, R.; WIRZ, S. A comparison between parents' and therapists' views of their child's individual seating systems. International Journal of Rehabilitation Research, London, v. 26, n. 3, p. 235-243, 2003. http://dx.doi. org/10.1097/00004356-200309000-00012

OSTENSJO, S.; CARLBERG, E. B.; VOLLESTAD, N. K. Everyday functioning in young children with cerebral palsy: functional skills, caregiver assistance, and modifications of the environment. Developmental Medicine and Child Neurology, London, v. 45, n. 9, p. 603-612, 2003. http://dx.doi.org/10.1111/j.1469-8749.2003.tb00964.x OSTENSJO, S.; CARLBERG, E. B.; VOLLESTAD, N. K. The use and impact of assistive devices and other environmental modifications on everyday activities and care in young children with cerebral palsy. Disability and Rehabilitation, London, v. 27, n. 14, p. 849-861, 2005. http://dx.doi.org/10.1080/09638280400018619. PMid:16096237

PAGLLUCA, L. M. F.; ARAGÃO, A. E. A.; ALMEIDA, P. C. Acessibilidade e deficiência física: identificação de barreiras arquitetônicas em áreas internas de hospitais de
Sobral, Ceará. Revista da Escola de Enfermagem da USP, São Paulo, v. 41, n. 4, p. 581-588, 2007.

PALISANO R. J. et al. Development and reliability of a system to classify gross motor function in children with cerebral palsy. Developmental Medicine and Child Neurology, London, v. 39, n. 4, p. 214-223, 1997. http:// dx.doi.org/10.1111/j.1469-8749.1997.tb07414.x

PALISANO, R. J. et al. Effect of environmental setting on mobility methods of children with cerebral palsy. Developmental Medicine and Child Neurology, London, v. 45, n. 2, p. 113-120, 2003. http://dx.doi. org/10.1111/j.1469-8749.2003.tb00914.x

PARETTE, H. P.; BROTHERSON, M. J. Familycentered and Culturally Responsive Assistive Technology Decision Making. Infants and Young Children, Frederick, v. 17, n. 4, p. 355-367, 2004. http://dx.doi. org/10.1097/00001163-200410000-00008

SALMINEN, A. L. et al. Mobility devices to promote activity and participation: a systematic review. Journal of Rehabilitation Medicine, Stockholm, v. 41, n. 9, p. 697-706, 2009. PMid:19774301. http://dx.doi. org/10.2340/16501977-0427

SILVA, G. R. F. et al. Entrevista como técnica de pesquisa qualitativa. Online Brazilian Journal of Nursing, Niterói, v. 5, n. 2, 2006. Disponível em: http://www.objnursing. uff.br/index.php/nursing/article/view/382

SKAR, L. Disabled children's perceptions of technical aids, assistance and peers in play situations. Scandinavian Journal of Caring Sciences, Hoboken, v. 16, n. 1, p. 27-33, 2002. http://dx.doi.org/10.1046/j.1471-6712.2002.00047.x

TURATO, E. R. Tratado de metodologia da pesquisa clinico-qualitativa. Petrópolis: Vozes, 2003.

VASCONCELOS, L. R.; PAGLLUCA, L. M. F. Mapeamento da acessibilidade do portador de limitação física a serviços básicos de saúde. Escola Anna Nery: Revista de Enfermagem, Rio de Janeiro, v. 10, n. 2, p. 494-500, 2006.

WIART, L. et al. Mothers' perceptions of their children's use of powered mobility. Physical \& Occupational Therapy in Pediatrics, London, v. 24, n. 4, p. 3-21, 2004. http:// dx.doi.org/10.1300/J006v24n04_02

\section{Contribuição dos Autores}

Mariana Volpini: Concepção do texto manuscrito, coleta de dados, organização e análise dos resultados, redação do texto. Marina de Brito Brandão: Organização e análise dos resultados, redação do texto. Lívia Álvares Rabelo Pereira: Coleta de dados. Marisa Cotta Mancini: Interpretação dos resultados, revisão do texto. Marcella Guimarães Assis: Orientação da pesquisa, interpretação dos resultados, revisão do texto. 